\title{
Exposure to Smoke During Development: Fetal Programming of Adult Disease
}

\author{
Hugo T. Bergen \\ Dept. of Human Anatomy \& Cell Science, University of Manitoba,
}

\begin{abstract}
It is well established that smoking has potent effects on a number of parameters including food intake, body weight, metabolism, and blood pressure. For example, it is well documented that 1) there is an inverse relationship between smoking and body weight, and 2) smoking cessation is associated with weight gain. However, there is increasing evidence that smoking can exert deleterious effects on energy balance through maternal exposure during fetal development. Specifically, there appears to be an increased incidence of metabolic disease (including obesity), and cardiovascular disease in children and adults that were exposed to smoke during fetal development. The present review will examine the relationship between maternal smoke and adult disease in offspring. The epidemiological studies highlighting this relationship will be reviewed as well as the experimental animal models that point to potential mechanisms underlying this relationship. A better understanding of how smoking effects changes in energy balance may lead to treatments to ameliorate the long-lasting effects of perinatal exposure to smoke as well as increasing the health benefits associated with smoking cessation.
\end{abstract}

\section{Smoking And The Fetal Origins Of Disease}

\section{Introduction - Fetal Programming of Adult Disease}

Recently there has been increased attention paid to the hypothesis that some diseases that have been considered to be diseases of adulthood (e.g., obesity, type II diabetes, cardiovascular disease, hypertension, and some cancers) may have their origins in fetal development. This is most commonly referred to as either the "developmental origins of disease" or the "fetal origins of disease" (1-7). The hypothesis states that the susceptibility to develop some diseases is determined in part by the intrauterine and early postnatal environment, i.e., perturbations to the early environment (e.g., nutritional deficits) can significantly increase susceptibility to develop disease later in life. The association between poor fetal and newborn growth and the subsequent development of obesity is a commonly cited example of this phenomenon $(7 ; 8)$. The epidemiological studies that reported this association led to the formulation of the "thrifty phenotype hypothesis" (9). This hypothesis stated that a poor nutritional environment for the fetus, brought on by either malnutrition or placental dysfunction, can induce an adaptive response that will optimize growth and development later in life. The adaptive response (which may include changes in circulating hormones, receptor sensitivity, regulatory enzymes, central nervous system changes), would lead to potential increased survival of the adult individual under conditions of marginal nutritional supply. However, under conditions of nutritional abundance the result will be maladaptive with increased incidence of obesity, hyperlipidemia, hypertension and type II diabetes in adulthood. 
One of the first and best documented examples of this phenomenon was the development of obesity in individuals 20 years after they were born during the Dutch famine of 1944-1945. Individuals were at greater risk of developing obesity following exposure to under-nutrition during late gestation and early post-natal periods (10). The last 30 years has seen numerous epidemiological studies outlining a relationship between gestational nutrition together with birth weight (as a marker of impaired fetal growth) and subsequent diseases such as obesity, type II diabetes, hypertension and cardiovascular disease to name a few $(1 ; 5$; 11-15) Epidemiological studies have now been bolstered by an increasing number of experimental studies demonstrating a relationship between perinatal nutrition and/or birth weight, and adult disease (2; 7; 16-19). The mechanism(s) responsible for translating fetal effects into adult disease are not well understood but several candidates include imprinting through epigenetic programming.

Most of the research, with respect to early programming of adult disease, has focused on nutritional challenges (under- and overnutrition) on the subsequent development of adult diseases. However, there is increasing evidence that long-lived effects of perinatal perturbations may not be limited to nutritional influences but may also include other influences such as maternal smoking. The present review will focus on the effects of maternal smoking on the subsequent development of diseases in the offspring. It should be noted that cigarette smoke contains numerous components that are biologically active. Although nicotine is a dominant factor in this regard, other components of smoke may also be involved in mediating the detrimental effects of smoke on fetal development and the subsequent promotion of disease into adulthood.

\section{Smoking and Obesity}

One of the first epidemiological studies that examined the effect of maternal smoking on the subsequent development of obesity was a birth cohort study of over 17,000 births and these individuals were tracked at 16 and 33 years of age (20). This study identified a significant effect of maternal smoking on the subsequent development of non-diabetic obesity, as well as an effect on diabetes (see below). In the offspring of mothers that smoked during pregnancy, there was significant increase in the incidence of obesity (at 33 years of age) and the magnitude of the effect was greater in the offspring of heavy smokers than the offspring of medium smokers. Similar results were obtained in a study of over 6,000 children (21). Specifically, there was a dose dependent association between maternal smoking during pregnancy and childhood obesity (5-7 yrs. of age) that was independent of a variety of lifestyle confounders or other risk factors for obesity. However, it is also known that maternal smoking can significantly impair fetal growth $(22 ; 23)$ and that low birth weight is itself associated with increased incidence of obesity later in life (24). In this clinical scenario, i.e., obesity in individuals born small for gestational age, the post-natal and early developmental period is characterized by a phenomenon referred to as "catch-up growth"(22; 24-26). Therefore, obesity due to maternal smoking may be secondary to the effects of maternal smoking on fetal growth; i.e., maternal smoking produces smaller babies and smaller babies are more susceptible to develop a variety of adult diseases. However, it should be noted that the relationship between maternal smoking during pregnancy and overweight in children is a complex one. Specifically, a more recent epidemiological study reported that the likelihood of being overweight at 4.5 years was almost doubled as a result of maternal smoking during pregnancy. Interestingly, the effect of maternal smoking on overweight was seen in normal birth weight children that 
had the greatest weight gain in the first few months of life as well as in high birth weight children that had the least amount of weight gain after birth (27). This suggests that maternal smoking may increase susceptibility to develop overweight and this can occur in normal birth weight as well as high birth weight children.

However, although catch-up growth may be a factor in the subsequent development of obesity, studies also suggest that the effect of maternal smoking on obesity in offspring can occur independently of catch-up growth (21). It was reported that infants exposed to maternal smoke had lighter birth weights but as they grew into adolescence they tended to have greater body mass index and this tendency increased with age (28). Importantly, studies have reported that the association between maternal smoking on obesity remains even when adjusted for birth weight; i.e, maternal smoking exerts an influence independent of its effects on fetal growth $(21 ; 28 ; 29)$. In a subsequent study it was also reported that the effects of maternal smoke on development of obesity was observed in children 5-7 years of age and that if mothers that otherwise smoked, abstained during pregnancy and then resumed smoking after childbirth, the association was no longer observed (30). This clearly suggests that intrauterine exposure to maternal smoke, rather than other family or lifestyle factors, can exert profound influences on regulation of energy balance that can be detected as early as 3 to 5 years of age $(30 ; 31)$. For example, the size of the effect of maternal smoking on childhood obesity was as great as that observed in studies linking obesity with frequent television viewing and playing video games (21).

In a study that examined the relationship of maternal smoking to obesity in American Indian children there was a significant effect of maternal smoking during pregnancy on overweight at three years of age (31). It is also of interest to note that the effect was independent of birth weight (and mother's pre-pregnancy weight). Given that smoking has also been linked to low birth weight and that low birth weight has been linked to obesity; the dissociation between these two variables in this study indicates that the effect of smoking is not simply through an effect on birth weight $(32 ; 33)$.

An important issue regarding the effect of maternal smoke on fetal development and subsequent health effects is determining the sensitivity of the fetus to the detrimental effects of smoke. From a public health perspective, it is vital to know whether smoking is harmful to the fetus in the first trimester when women who smoke and do not know that they are pregnant, will be unintentionally exposing their fetuses to the harmful effects of smoke. In a recent study it was reported that there was no difference in the effect of maternal smoking between mothers that smoked throughout pregnancy and those that smoked only during the first trimester on subsequent development of obesity (34). These results could not be explained by other potentially confounding factors such as breastfeeding, watching television, playing video games, and parental obesity. This suggests that during the first three months of pregnancy the fetus is particularly sensitive to the detrimental effects of exposure to maternal smoke. In a recent prospective study, maternal smoking during early pregnancy was associated with overweight at three years of age (35). Furthermore, the effect was observed even when adjusted for other factors such as ethnicity, income, education and childhood diet. In contrast, an increased incidence of obesity was not observed in children of mothers who quit smoking prior to conception (as compared to never smokers). These studies suggest that the detrimental effects of maternal smoking on fetal development may occur in the first trimester. Therefore, it seems prudent that women should be encouraged to quit smoking before conception; as is 
the case with alcohol consumption.

\section{Smoking and Diabetes}

One of the first epidemiological studies that identified a link between the effect of maternal smoking and the subsequent development of diabetes was a birth cohort study of over 17,000 births. In addition to identifying maternal smoking as a risk factor for obesity, this study identified a significant effect of maternal smoking on the subsequent development of early adult onset diabetes (20). For example, if a mother smoked more than 10 cigarettes a day while pregnant, there was a four-fold greater chance that the offspring would develop diabetes, as compared to offspring that were not exposed to smoke. Moreover in a more recent study aimed at examining the effects of smoking in association with other drugs (alcohol and illicit drugs), prenatal exposure to nicotine, but not alcohol, had a significant effect on subsequent BMI and similar to other studies, a dose response relationship was detected (36). Taken together, these epidemiological studies suggest that prenatal exposure to smoke has a longlasting effect on body weight. Specifically, there is a greater incidence of overweight and obesity in those exposed to maternal smoke and that there is a significant dose-response relationship. The mechanism for the effect is not known however the authors speculated that it may be related to either fetal malnutrition or the toxicity of smoke on the fetus.

\section{Smoking and Hypertension}

In addition to nicotine's effect on the subsequent development of obesity, maternal smoking also appears to have an effect on the subsequent development of cardiovascular disease; specifically hypertension. A number of studies have provided evidence that low birth weight is associated with hypertension later in life (37). Therefore, since smoking during pregnancy acts to decrease birth weight, the effects of smoking on subsequent hypertension could occur indirectly through effects on birth weight. In a prospective cohort study with over 1700 pregnant women, a significant effect of maternal smoking during pregnancy on blood pressure at six years of age was found and interestingly, this was not entirely due to the effect of smoking on birth weight (38). In a second prospective study of over 3,800 children, a relationship between smoking during pregnancy and increased blood pressure at 5 years of age was reported and the effect was independent of birth weight (39).

While the above studies highlight the detrimental effects of maternal smoking on the subsequent susceptibility to develop obesity, diabetes, and hypertension, the mechanism underlying this effect is not well understood and a number of possibilities have been proposed. Clearly, a better understanding of how maternal smoking, and/or nicotine, effects changes in energy balance, metabolism, and blood pressure, may lead to treatments to ameliorate the long-lasting effects of perinatal exposure to smoke as well as increasing the health benefits associated with smoking cessation. In any case, recommendations to stop smoking are particularly relevant in women that are planning or attempting to become pregnant.

\section{Smoking and Fetal Origins of Disease: Potential Mechanisms}

A. Decreased fetal growth - As mentioned above, a number of studies have found evidence of a link between low birth weight and subsequent development of obesity (Reviewed in $(2 ; 7 ; 40 ; 41)$ ). Since maternal smoking is associated with decreased fetal growth, the increased incidence of obesity may be a secondary result of being born small for gestational age. However it should be noted that while low birth weight may play a role in subsequent disease processes, there is evidence that the detrimental effects of smoking may occur independently of low 
birth weight (see above). In any case, the mechanism(s) underlying the effect of nicotine on birth weight is (are) not well understood and a number of possibilities clearly exist. The possibilities highlighted below are neither exhaustive nor mutually exclusive.

\section{Low birth weight is due to smoking-} derived nicotine effects on maternal appetite and energy expenditure. Nicotine is considered to have an inhibitory effect on body weight gain. This is supported by the association that smokers weigh less than non-smokers and cessation of smoking is accompanied by significant weight gain (42). There is evidence to suggest that the mechanism for nicotine's effect on body weight may involve both an increase in energy expenditure and a decrease in food intake (43-48). Therefore, during pregnancy the combination of nicotine-induced suppression of maternal food intake and increased energy expenditure may collaborate to be sufficient to produce poor or under nutrition which then leads to decreased fetal growth. The effect of smoking appears to be an effect of intrauterine growth retardation and not an effect on pre-term delivery (32).

2. Low birth weight is due to detrimental effects of nicotine on placental structure and function. A second possible mechanism responsible for smoking's effect on decreased fetal growth may be at the level of the placenta; i.e., through impaired delivery of oxygen and/or nutrients to the fetus. Nicotine via activation of nicotinic acetylcholine receptors, can exert a vasoconstrictive effect on placental arterial supply leading to attenuation of oxygen delivery to the fetus which in turn could lead to decreased fetal growth (49-51). Smoking is also associated with increased carbon monoxide in maternal blood which in turn reduces oxygen delivery to the fetus leading to decreased fetal growth. Smoking decreases uterine blood flow to the placenta which could play a role in decreased fetal growth observed produced in the smoking pregnant woman $(50 ; 52$; 53). There are also a number of studies that have reported that smoking is associated with marked changes in placental structure and function. For example, smoking is associated with a significant increase in the thickness of the villous membrane which could predictably lead to a decrease in gas and nutrient exchange across the placenta and impaired fetal growth $(54 ; 55)$. Smoking also exerts detrimental effects on the trophoblast component of the placenta as well as decreasing the area for diffusion between the maternal blood and fetal blood (5659). For example, trophoblast cell differentiation is impaired with maternal smoking and this effect can occur early in the development of the placenta $(58 ; 59)$. Structural changes of the placenta may act to decrease gas exchange, as well as nutrient exchange (e.g., amino acid transport) across the placenta (60) Taken together it is clear that smoking during pregnancy has significant effects on placental development that leads to significant changes in structure and function that may result in detrimental effects on fetal growth and well-being

\section{Low birth weight is due to} detrimental effects of nicotine on fetal metabolism. A third possibility is that nicotine or other constituents of smoke may have detrimental or toxic effects on fetal metabolism that impair growth of the fetus. Nicotine readily crosses the placenta and therefore it could potentially exert direct effects on fetal tissues (49). For example, it is becoming increasingly evident that the endocrine status of the fetus is altered significantly in response to maternal smoking $(61 ; 62)$. In particular, leptin, growth hormone and insulin-like growth factor (IGF) levels in the fetal compartment are altered in response to maternal smoke (61). It was suggested that decreased IGF levels detected in cord blood associated with maternal smoking may play a role in limiting fetal growth 
(62). Of particular interest is the effect of maternal smoke and/or nicotine on leptin levels present in cord blood. As discussed below, leptin may exert profound influences on development of the neural systems underlying regulation of appetite and metabolism. Taken together, it is clear that maternal smoking may exert potent and detrimental effects on fetal growth via a number of mechanisms.

\section{B. Perturbations in Central Regulatory} Circuits - Most of the studies exploring potential mechanisms underlying smoking and disease later in life have focused on obesity. It is well established from animal studies that nicotine can act within the central nervous system to decrease food intake and body weight (63-66). Although most studies examining nicotine's effect on energy balance are acute studies performed in adult animals, there is an increasing evidence that exposure to nicotine during development can produce long lasting perturbations in brain neurochemistry including dopamine, serotonin, acetylcholine, and a variety of neuropeptides, as well as leptin receptors (67-77). These changes could potentially lead to long term changes in the neural regulation of energy balance, i.e., nicotine either directly or indirectly may alter appetite or self regulation of food intake in infants exposed to maternal smoke. It has been proposed that smoking acts by means of metabolic imprinting on the system controlling food intake and satiety. A number of rodent studies have provided evidence in support of the hypothesis that maternal nicotine has long-lasting effects on neurotransmitter systems that are implicated in the regulation of energy balance. In addition there is recent evidence suggesting that programming of the neural circuits that regulate energy balance occurs in the perinatal period and that metabolic or nutritional deficits result in altered regulation of energy balance, including appetite $(78 ; 79)$. For example, a study in Rhesus monkeys demonstrated that maternal nicotine exposure had a significant effect on gene expression of neuropeptides (neuropeptide $\mathrm{Y}$ and proopiomelanocortin) in the hypothalamus (74).. It is well established that these hypothalamic neuropeptides can exert potent effects on the regulation of energy balance and it was proposed that altered regulation of these neuropeptides may play a role in decreased body weight associated with maternal smoking. Interestingly, it was also reported that circulating leptin levels were reduced following nicotine treatment, similar to the situation that occurs in humans $(61 ; 74)$. Decreased leptin levels in response to nicotine is of particular interest since a number of recent studies have suggested that leptin may play a critical role in the development of brain circuits that regulate energy balance (80-83). In genetically obese mice that lack leptin (i.e., ob/ob mice), exogenous administration of leptin had marked effects on synaptic contacts between excitatory and inhibitory hypothalamic neurons that regulate energy balance (82). The importance of leptin in development is further bolstered by recent studies demonstrating that treatment with leptin during the perinatal period can offset developmental programming that occurs as a result of maternal undernourishment (84). Clearly, the role of leptin as a hormone that regulates neuronal development is a topic of increasing interest and if nicotine alters circulating leptin during development, this could have long-term consequences (85). In this regard it is also interesting to note that under-nutrition of mouse dams (which decreases circulating leptin) was associated with obesity in the pups when they were subsequently fed a high-fat diet (86). This may be a mechanism by which nutritional perturbations in the perinatal period, for example brought on by maternal smoking, may have long-lasting effects. Taken together these results suggest that smoking may have long lasting effects on the neural circuits responsible for regulating food intake and 
metabolism.

\section{Conclusion}

It is becoming increasingly clear that fetal exposure to nicotine has numerous consequences to the detriment of the health of the fetus and that these effects may last well into adulthood. These effects include increased incidence of obesity, cardiovascular disease, and noninsulin dependent diabetes mellitus. It is not well understood how smoking may produce these long-lasting effects but it is evident that the fetal environment is of tremendous importance during the developmental period in determining health throughout the life of the individual. In any case, women who are planning a pregnancy now have additional reasons to stop smoking in addition to the health benefits that they will receive from nicotine abstinence.

\section{BIBLIOGRAPHY}

1. Gluckman PD, Hanson MA. Living with the past: evolution, development, and patterns of disease. Science 2004;305:17331736.

2. Remacle C, Bieswal F, Reusens B. Programming of obesity and cardiovascular disease. Int $J$ Obes Relat Metab Disord 2004;28 Suppl 3:S46-S53.

3. Barker DJ, Osmond C, Law CM. The intrauterine and early postnatal origins of cardiovascular disease and chronic bronchitis. J Epidemiol Community Health 1989;43:237240.

4. Hales CN, Barker DJ. The thrifty phenotype hypothesis. Br Med Bull 2001;60:5-20.

5. Ozanne SE, Fernandez-Twinn D, Hales CN. Fetal growth and adult diseases. Semin Perinatol 2004;28:81-87.

6. Plagemann A. 'Fetal programming' and 'functional teratogenesis': on epigenetic mechanisms and prevention of perinatally acquired lasting health risks. J Perinat Med 2004;32:297-305.

7. Stocker CJ, Arch JR, Cawthorne MA. Fetal origins of insulin resistance and obesity. Proc Nutr Soc 2005;64:143-151.

8. Ong KK, Dunger DB. Perinatal growth failure: the road to obesity, insulin resistance and cardiovascular disease in adults. Best Pract Res Clin Endocrinol Metab 2002;16:191-207.

9. Hales CN, Barker DJ. Type 2 (noninsulin-dependent) diabetes mellitus: the thrifty phenotype hypothesis. Diabetologia 1992;35:595-601.

10. Ravelli GP, Stein ZA, Susser MW. Obesity in young men after famine exposure in utero and early infancy. $N$ Engl $J$ Med 1976;295:349-353.

11. Barker DJ. In utero programming of chronic disease. Clin Sci (Lond) 1998;95:115-128.

12. Aerts L, Van Assche FA. Intra-uterine transmission of disease. Placenta 2003;24:905-911.

13. Simmons R. Developmental origins of adult metabolic disease. Endocrinol Metab Clin North Am 2006;35:193-204.

14. Sallout B, Walker M. The fetal origin of adult diseases. $J$ Obstet Gynaecol 2003;23:555-560.

15. Barker DJ, Winter PD, Osmond C, Margetts B, Simmonds SJ. Weight in infancy and death from ischaemic heart disease. Lancet 1989;2:577-580.

16. Levin BE. Metabolic imprinting on genetically predisposed neural circuits perpetuates obesity. Nutrition 2000;16:909-915.

17. McMillen IC, Robinson JS. Developmental origins of the metabolic syndrome: prediction, plasticity, and programming. Physiol Rev 2005;85:571-633. 
18. McArdle HJ, Andersen HS, Jones H, Gambling L. Fetal Programming: Causes and Consequences as Revealed by Studies of Dietary Manipulation in Rats - A Review. Placenta 2006;27 Suppl A:S56S60

19. Armitage JA, Khan IY, Taylor PD, Nathanielsz PW, Poston L. Developmental programming of the metabolic syndrome by maternal nutritional imbalance: how strong is the evidence from experimental models in mammals? $J$ Physiol 2004;561:355-377.

20. Montgomery SM, Ekbom A. Smoking during pregnancy and diabetes mellitus in a British longitudinal birth cohort. BMJ 2002;324:26-27.

21. von Kries R, Toschke AM, Koletzko B, Slikker W, Jr. Maternal smoking during pregnancy and childhood obesity. Am J Epidemiol 2002;156:954-961.

22. Vik T, Jacobsen G, Vatten L, Bakketeig LS. Pre- and post-natal growth in children of women who smoked in pregnancy. Early Human Development 1996;45:245255.

23. Ellard GA, Johnstone FD, Prescott RJ, Ji-Xian W, Jian-Hua M. Smoking during pregnancy: the dose dependence of birthweight deficits. $\mathrm{Br} J$ Obstet Gynaecol 1996;103:806-813.

24. Ong KK, Ahmed ML, Emmett PM, Preece MA, Dunger DB. Association between postnatal catch-up growth and obesity in childhood: prospective cohort study. BMJ 2000;320:967-971.

25. Dulloo AG, Jacquet J, Montani JP. Pathways from weight fluctuations to metabolic diseases: focus on maladaptive thermogenesis during catch-up fat. Int $J$ Obes Relat Metab Disord 2002;26 Suppl 2:S46-S57.

26. Ross MG, Desai M. Gestational programming: population survival effects of drought and famine during pregnancy. Am J Physiol Regul Integr Comp Physiol 2005;288:R25-33.

27. Dubois L, Girard M. Early determinants of overweight at 4.5 years in a population-based longitudinal study. Int $J$ Obes (Lond) 2006;30:610-617.

28. Power C, Jefferis BJ. Fetal environment and subsequent obesity: a study of maternal smoking. Int $J$ Epidemiol 2002;31:413-419.

29. Wideroe M, Vik T, Jacobsen G, Bakketeig LS. Does maternal smoking during pregnancy cause childhood overweight? Paediatric and Perinatal Epidemiology 2003;17:171-179.

30. Toschke AM, Koletzko B, Slikker W, Jr., Hermann M, von Kries R. Childhood obesity is associated with maternal smoking in pregnancy. Eur $J$ Pediatr 2002;161:445-448.

31. Adams AK, Harvey HE, Prince RJ. Association of maternal smoking with overweight at age $3 \mathrm{y}$ in American Indian children. $A m J$ Clin Nutr 2005;82:393-398.

32. Horta BL, Victora CG, Menezes AM, Halpern R, Barros FC. Low birthweight, preterm births and intrauterine growth retardation in relation to maternal smoking. Paediatr Perinat Epidemiol 1997;11:140-151.

33. Fox NL, Sexton M, Hebel JR. Prenatal exposure to tobacco: I. Effects on physical growth at age three. Int $J$ Epidemiol 1990;19:66-71.

34. Toschke AM, Montgomery SM, Pfeiffer U, von Kries R. Early intrauterine exposure to tobaccoinhaled products and obesity. $A m \mathrm{~J}$ Epidemiol 2003;158:1068-1074.

35. Oken E, Huh SY, Taveras EM, RichEdwards JW, Gillman MW. Associations of maternal prenatal smoking with child adiposity and 
blood pressure. Obes Res 2005;13:2021-2028.

36. Hill SY, Shen S, Locke Wellman J, Rickin E, Lowers L. Offspring from families at high risk for alcohol dependence: increased body mass index in association with prenatal exposure to cigarettes but not alcohol. Psychiatry Res 2005; 135:203-216.

37. Law CM, Shiell AW. Is blood pressure inversely related to birth weight? The strength of evidence from a systematic review of the literature. J Hypertens 1996;14:935-941.

38. Blake KV, Gurrin LC, Evans SF, Beilin LJ, Landau LI, Stanley FJ, Newnham JP. Maternal cigarette smoking during pregnancy, low birth weight and subsequent blood pressure in early childhood. Early Hum Dev 2000;57:137-147.

39. Lawlor DA, Najman JM, Sterne J, Williams GM, Ebrahim S, Smith GD. Associations of Parental, Birth, and Early Life Characteristics With Systolic Blood Pressure at 5 Years of Age: Findings From the MaterUniversity Study of Pregnancy and Its Outcomes. Circulation 2004;110:2417-2423.

40. Oken E, Gillman MW. Fetal origins of obesity. Obes Res 2003;11:496506.

41. Levy-Marchal C, Jaquet D, Czernichow P. Long-term metabolic consequences of being born small for gestational age. Semin Neonatol 2004;9:67-74.

42. Albanes D, Jones DY, Micozzi MS, Mattson ME. Associations between smoking and body weight in the US population: analysis of NHANES II. Am J Public Health 1987;77:439-444.

43. Hofstetter A, Schutz Y, Jequier E, Wahren J. Increased 24-hour energy expenditure in cigarette smokers. $N$ Engl $J$ Med 1986;314:79-82.
44. Jessen A, Buemann B, Toubro S, Skovgaard IM, Astrup A. The appetite-suppressant effect of nicotine is enhanced by caffeine. Diabetes Obes Metab 2005;7:327333.

45. Grunberg NE. Nicotine as a psychoactive drug: appetite regulation. Psychopharmacol Bull 1986;22:875-881.

46. Klesges RC, Eck LH, Isbell TR, Fulliton W, Hanson CL. Smoking status: effects on the dietary intake, physical activity, and body fat of adult men. Am $J$ Clin Nutr 1990;51:784-789.

47. Leischow SJ, Stitzer ML. Effects of smoking cessation on caloric intake and weight gain in an i n a t i e n t u n i t. Psychopharmacology (Berl) 1991;104:522-526.

48. Collins LC, Walker J, Stamford BA. Smoking multiple high- versus low-nicotine cigarettes: impact on resting energy expenditure. Metabolism 1996;45:923-926.

49. Lambers DS, Clark KE. The maternal and fetal physiologic effects of nicotine. Semin Perinatol 1996;20:115-126.

50. Andersen KV, Hermann N. Placenta flow reduction in pregnant smokers. Acta Obstet Gynecol Scand 1984;63:707-709.

51. Lindblad A, Marsal K, Andersson KE. Effect of nicotine on human fetal blood flow. Obstet Gynecol 1988;72:371-382.

52. Castro LC, Allen R, Ogunyemi D, Roll K, Platt LD. Cigarette smoking during pregnancy: acute effects on uterine flow velocity waveforms. Obstet Gynecol 1993;81:551-555.

53. Salafia C, Shiverick K. Cigarette smoking and pregnancy II: vascular effects. Placenta 1999;20:273-279.

54. Jauniaux E, Burton GJ. The effect of smoking in pregnancy on early placental morphology. Obstet 
Gynecol 1992;79:645-648.

55. Burton GJ, Palmer ME, Dalton KJ. Morphometric differences between the placental vasculature of nonsmokers, smokers and ex-smokers. Br J Obstet Gynaecol 1989;96:907-915.

56. Larsen LG, Clausen HV, Jonsson L. Stereologic examination of placentas from mothers who smoke during pregnancy. Am $J$ Obstet Gynecol 2002;186:531-537.

57. Bush PG, Mayhew TM, Abramovich DR, Aggett PJ, Burke MD, Page KR. A quantitative study on the effects of maternal smoking on placental morphology and cadmium concentration. Placenta 2000;21:247-256.

58. Genbacev O, Bass KE, Joslin RJ, Fisher SJ. Maternal smoking inhibits early human cytotrophoblast differentiation. Reprod Toxicol 1995;9:245-255.

59. Genbacev O, McMaster MT, Zdravkovic $\mathrm{T}$, Fisher SJ. Disruption of oxygen-regulated responses underlies pathological changes in the placentas of women who smoke or who are passively exposed to smoke during pregnancy. Reprod Toxicol 2003;17:509-518.

60. Pastrakuljic A, Derewlany LO, Koren G. Maternal Cocaine Use and Cigarette Smoking in Pregnancy in Relation to Amino Acid Transport and Fetal Growth. Placenta 1999;20:499-512.

61. Mantzoros CS, Varvarigou A, Kaklamani VG, Beratis NG, Flier JS. Effect of birth weight and maternal smoking on cord blood leptin concentrations of full-term and preterm newborns. $J$ Clin Endocrinol Metab 1997;82:28562861.

62. Coutant R, Boux de Casson F, Douay $\mathrm{O}$, Mathieu E, Rouleau S, Beringue F, Gillard P, Limal JM, Descamps P. Relationships between Placental
GH Concentration and Maternal Smoking, Newborn Gender, and Maternal Leptin: Possible Implications for Birth Weight. $J$ Clin Endocrinol Metab 2001;86:4854-4859.

63. Sanigorski A, Fahey R, CameronSmith D, Collier GR. Nicotine treatment decreases food intake and body weight via a leptinindependent pathway in Psammomys obesus. Diabetes Obes Metab 2002;4:346-350.

64. Miyata G, Meguid MM, Fetissov SO, Torelli GF, Kim HJ. Nicotine's effect on hypothalamic neurotransmitters and appetite regulation. Surgery 1999;126:255263.

65. Yang ZJ, Blaha V, Meguid MM, Oler A, Miyata G. Infusion of nicotine into the LHA enhances dopamine and 5-HT release and suppresses food intake. Pharmacol Biochem Behav 1999;64:155-159.

66. Winders SE, Grunberg NE. Effects of nicotine on body weight, food consumption and body composition in male rats. Life Sci 1990;46:1523-1530.

67. Slotkin TA, Pinkerton KE, Auman JT, Qiao D, Seidler FJ. Perinatal exposure to environmental tobacco smoke upregulates nicotinic cholinergic receptors in monkey brain. Brain Res Dev Brain Res 2002;133:175-179.

68. Slotkin TA, Seidler FJ, Qiao D, Aldridge JE, Tate CA, Cousins MM, Proskocil BJ, Sekhon HS, Clark JA, Lupo SL and others. Effects of prenatal nicotine exposure on primate brain development and attempted amelioration with supplemental choline or vitamin $\mathrm{C}$ : neurotransmitter receptors, cell signaling and cell development biomarkers in fetal brain regions of $\mathrm{rh}$ e s u s $\mathrm{m}$ o $\mathrm{n} \mathrm{k}$ e y s. Neuropsychopharmacology 
2005;30:129-144.

69. Muneoka K, Ogawa T, Kamei K, Mimura Y, Kato H, Takigawa M. Nicotine exposure during pregnancy is a factor which influences serotonin transporter density in the rat brain. Eur $J$ Pharmacol 2001;411:279-282.

70. Muneoka K, Ogawa T, Kamei K, Muraoka S, Tomiyoshi R, Mimura Y, Kato H, Suzuki MR, Takigawa M. Prenatal nicotine exposure affects the development of the central serotonergic system as well as the dopaminergic system in rat offspring: involvement of route of drug administrations. Brain Res Dev Brain Res 1997;102:117-126.

71. Muneoka K, Nakatsu T, Fuji J, Ogawa T, Takigawa M. Prenatal administration of nicotine results in dopaminergic alterations in the neocortex. Neurotoxicol Teratol 1999;21:603-609.

72. Yanai J, Pick CG, Rogel-Fuchs Y, Zahalka EA. Alterations in hippocampal cholinergic receptors and hippocampal behaviors after early exposure to nicotine. Brain Res Bull 1992;29:363-368.

73. Cohen G, Roux JC, Grailhe R, Malcolm G, Changeux JP, Lagercrantz H. Perinatal exposure to nicotine causes deficits associated with a loss of nicotinic receptor function. Proc Natl Acad Sci U S A 2005;102:3817-3821.

74. Grove KL, Sekhon HS, Brogan RS, Keller JA, Smith MS, Spindel ER. Chronic maternal nicotine exposure alters neuronal systems in the arcuate nucleus that regulate feeding behavior in the newborn rhesus macaque. J Clin Endocrinol Metab 2001;86:5420-5426.

75. Xu Z, Seidler FJ, Ali SF, Slikker W, Jr., Slotkin TA. Fetal and adolescent nicotine administration: effects on CNS serotonergic systems. Brain Res 2001;914:166178.
76. Abreu-Villaca Y, Seidler FJ, Tate CA, Cousins MM, Slotkin TA. Prenatal nicotine exposure alters the response to nicotine administration in adolescence: effects on cholinergic systems during exposure and withdrawal. Neuropsychopharmacology 2004;29:879-890.

77. Li MD, Kane JK. Effect of nicotine on the expression of leptin and forebrain leptin receptors in the rat. Brain Res 2003;991:222-231.

78. Das UN. Pathophysiology of metabolic syndrome $\mathrm{X}$ and its links to the perinatal period. Nutrition 2005;21:762-773.

79. Cripps RL, Martin-Gronert MS, Ozanne SE. Fetal and perinatal programming of appetite. Clin Sci (Lond) 2005;109:1-11.

80. Ahima RS, Bjorbaek C, Osei S, Flier JS. Regulation of neuronal and glial proteins by leptin: implications for brain development. Endocrinology 1999; 140:2755-2762.

81. Bouret SG, Draper SJ, Simerly RB. Trophic action of leptin on hypothalamic neurons that regulate feeding. Science 2004;304:108110.

82. Pinto S, Roseberry AG, Liu H, Diano $\mathrm{S}$, Shanabrough $\mathrm{M}$, Cai $\mathrm{X}$, Friedman JM, Horvath TL. Rapid rewiring of arcuate nucleus feeding circuits by leptin. Science 2004;304:110-115.

83. Horvath TL, Bruning JC. Developmental programming of the hypothalamus: a matter of fat. Nat Med 2006;12:52-53.

84. Vickers MH, Gluckman PD, Coveny AH, Hofman PL, Cutfield WS, Gertler A, Breier BH, Harris M. Neonatal leptin treatment reverses developmental programming. Endocrinology 2005;146:42114216.

85. Bouret SG, Simerly RB. Minireview: Leptin and development of 
16 Bergen $\mathrm{H}$

hypothalamic feeding circuits. Endocrinology 2004;145:26212626.

86. Yura S, Itoh H, Sagawa N, Yamamoto $\mathrm{H}$, Masuzaki H, Nakao K, Kawamura M, Takemura M, Kakui $\mathrm{K}$, Ogawa $\mathrm{Y}$ and others. Role of premature leptin surge in obesity resulting from intrauterine undernutrition. Cell Metab 2005;1:371-378. 